\title{
Transcriptome analysis and identification of genes associated with fruiting branch internode elongation in upland cotton
}

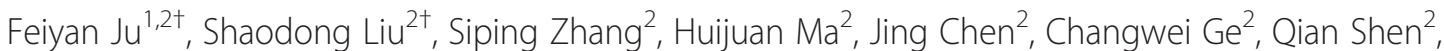
Xiaomeng Zhang ${ }^{2}$, Xinhua Zhao ${ }^{2^{*}}$, Yongjiang Zhang ${ }^{1^{*}}$ and Chaoyou Pang ${ }^{2^{*}}$

\begin{abstract}
Background: Appropriate plant architecture can improve the amount of cotton boll opening and allow increased planting density, thus increasing the level of cotton mechanical harvesting and cotton yields. The internodes of cotton fruiting branches are an important part of cotton plant architecture. Thus, studying the molecular mechanism of internode elongation in cotton fruiting branches is highly important.

Results: In this study, we selected internodes of cotton fruiting branches at three different stages from two cultivars whose internode lengths differed significantly. A total of 76,331 genes were detected by transcriptome sequencing. By KEGG pathway analysis, we found that DEGs were significantly enriched in the plant hormone signal transduction pathway. The transcriptional data and qRT-PCR results showed that members of the GH3 gene family, which are involved in auxin signal transduction, and CKX enzymes, which can reduce the level of CKs, were highly expressed in the cultivar XLZ77, which has relatively short internodes. Genes related to ethylene synthase (ACS), EIN2/3 and ERF in the ethylene signal transduction pathway and genes related to JAR1, COI1 and MYC2 in the JA signal transduction pathway were also highly expressed in XLZ77. Plant hormone determination results showed that the IAA and CK contents significantly decreased in cultivar XLZ77 compared with those in cultivar L28, while the ACC (the precursor of ethylene) and JA contents significantly increased. GO enrichment analysis revealed that the GO categories associated with promoting cell elongation, such as cell division, the cell cycle process and cell wall organization, were significantly enriched, and related genes were highly expressed in L28. However, genes related to the sphingolipid metabolic process and lignin biosynthetic process, whose expression can affect cell elongation, were highly expressed in XLZ77. In addition, 2067 TFs were differentially expressed. The WRKY, ERF and bHLH TF families were the top three largest families whose members were active in the two varieties, and the expression levels of most of the genes encoding these TFs were upregulated in XLZ77.

(Continued on next page)
\end{abstract}

\footnotetext{
* Correspondence: zhaoxinhua1968@126.com; yongjiangzh@sina.com; chypang@163.com

${ }^{\dagger}$ Feiyan Ju and Shaodong Liu contributed equally to this work.

${ }^{2}$ State Key Laboratory of Cotton Biology, Institute of Cotton Research, Chinese Academy of Agricultural Sciences, Anyang 455112, Henan, China ${ }^{1}$ State Key Laboratory of Cotton Biology (Hebei Base)/College of Agronomy, Hebei Agricultural University, Baoding 071001, Hebei, China
}

(C) The Author(s). 2019 Open Access This article is distributed under the terms of the Creative Commons Attribution 4.0 International License (http://creativecommons.org/licenses/by/4.0/), which permits unrestricted use, distribution, and reproduction in any medium, provided you give appropriate credit to the original author(s) and the source, provide a link to the Creative Commons license, and indicate if changes were made. The Creative Commons Public Domain Dedication waiver (http://creativecommons.org/publicdomain/zero/1.0/) applies to the data made available in this article, unless otherwise stated. 


\begin{abstract}
(Continued from previous page)
Conclusions: Auxin and CK are positive regulators of internode elongation in cotton branches. In contrast, ethylene and JA may act as negative regulators of internode elongation in cotton branches. Furthermore, the WRKY, ERF and bHLH TFs were identified as important inhibitors of internode elongation in cotton. In XLZ77(a short-internode variety), the mass synthesis of ethylene and amino acid conjugation of auxin led to the inhibition of plant cell elongation, while an increase in JA content and degradation of CKs led to a slow rate of cell division, which eventually resulted in a phenotype that presented relatively short internodes on the fruiting branches. The results of this study not only provide gene resources for the genetic improvement of cotton plant architecture but also lay a foundation for improved understanding of the molecular mechanism of the internode elongation of cotton branches.
\end{abstract}

Keywords: Cotton, Plant architecture, RNA-Seq, Internode elongation, Plant hormone, TFs

\section{Background}

Cotton (Gossypium hirsutum L.) is grown worldwide and is an important fiber crop [1]. Appropriately increasing the planting density of cotton plants represents an effective method for increasing cotton yields. However, broad and loose cotton plant architecture has become the key factor limiting increased cotton planting density. Therefore, appropriate plant architecture and colony structure are important for the cultivation of high-yielding cotton.

Plant architecture is a comprehensive representation of plant morphology and structure, physiological and ecological functions, etc. Plant architecture is a key determinant of light reception, photosynthate production, and nutrient partitioning and plays an important role in crop yield, product quality, and cultivation management [2]. In higher plants, formation of plant architecture also encompasses plant morphology-related organs throughout the whole growth and development of the plants, especially the formation, shape and location of the branches, leaves and flowers [3]. Overall, cotton plant architecture comprises several growth components, such as the height of the main stem, both the number and length of the fruiting branches and roots, the internode length of both the main stem and fruiting branches, and the distribution of cotton bolls throughout the whole plant, as well as the cotton growth structure and boll formation. The effects of plant architecture on lint yield are especially important [4]. Architecture can significantly affect the light distribution within and penetration into a crop canopy and thus can alter plant growth, biomass partitioning, boll distribution, and yield potential [5].

Plant hormones such as auxin, gibberellins (GAs), brassinolide and cytokinins (CKs) play important roles in the process of plant type formation; specifically, these hormones play important roles in the process of plant dwarfing, stem-leaf angle determination, and lobulation, while ethylene (ET) and abscisic acid (ABA) exert many inhibitory effects $[6,7]$. Plant height is determined by several developmental factors; specifically, stem elongation due to cell division and expansion (EXP) of both the shoot apical meristem (SAM) and the intermediate meristem play decisive roles. Stem elongation is controlled by several hormones, including GAs, brassinosteroids, auxin, and strigolactones (SLs) [8]. Relatively little is known about the molecular mechanisms controlling the growth of intercalary meristems, but this process is triggered by ET and promoted by GA [9]. In the case of deepwater rice, GA induces internode growth by promoting both cell division and cell elongation [10]. Oscen 1 and Oscen2, which are members of the TERMINAL FLOWER 1 (TFL1)/CENTRORADIALIS (CEN) gene family in rice, exhibit distinct expression patterns mainly in secondary meristems. Overexpression of Oscen 1 and Oscen 2 in transgenic rice plants results in increased numbers of shorter internodes, suggesting that these genes regulate the development of basic structures by stimulating the activities of secondary meristems in the uppermost phytomers [11]. The downregulation of GA biosynthesis-related genes in cotton inhibits cell elongation, reduces plant height and shortens internode lengths, which indicates that GA has an important effect on internode elongation of the main stem in cotton plants [1].

In terms of shoot architecture, the SAM determines plant phyllotaxy and impacts axillary meristem (AM) formation. During leaf development, an AM can develop in the axil and subsequently give rise to a secondary shoot. Lateral shoot outgrowth is fundamentally important for controlling shoot architecture [8]. By locating and cloning the GbAF gene (which controls the axillary flowering phenotype) of Gossypium barbadense L. and the GhCB gene (which controls the clustered boll phenotype) of Gossypium hirsutum L., researchers observed that different phenotypes were caused by mutations at different SNP loci at the same locus, which is homologous with SELF-PRUNING (SP) in tomato; moreover, silencing GoSP in Gossypium barbadense L. and Gossypium hirsutum L. transformed the plant architecture such that plant growth was limited [12]. The above mentioned studies focused mainly on the elongation of the internode of both the main stem and zero-type fruiting branches. No studies 
have investigated the physiological and transcriptional regulatory mechanisms that govern the internode elongation of indefinite fruiting branches of cotton.

In this study, two cotton plant varieties whose fruiting branch lengths significantly differ but whose heights do not significantly differ were used to identify and analyze the genes and related metabolic pathways involved in internode elongation via RNA Sequencing (RNA-Seq) techniques. The endogenous hormone contents and analysis of both transcription factors (TFs) and related genes revealed the molecular mechanism of internode elongation of cotton fruiting branches. Together, the results provide a valuable resource for further identification of genes related to internode elongation of cotton branches.

\section{Results}

Differences in the internode lengths of fruiting branches between genotypes

The differences in plant architecture were very significant between the two varieties (Fig. 1a). The L28 variety had longer fruiting branch internodes and loose plant architecture; the XLZ77 variety had shorter fruiting branch internodes and compact plant architecture. However, there was no significant difference in plant height between the two varieties. We measured the length of the first internode of each branch of both varieties (Fig. 1b); the internode of L28 gradually elongated until reaching the sixth branch, after which the length essentially stabilized at approximately $14 \mathrm{~cm}$. On the other hand, the internode length of XLZ77 was stabilized at approximately $3 \mathrm{~cm}$ at the fourth branch. To explain the differences in internode lengths of the fruiting branches, we selected the first internode of the first, second and third branches from the top for transcriptome sequencing (Fig. 1c).

\section{RNA-Seq analysis and gene annotation}

Approximately $1.05 \times 10^{9}$ raw reads of $150 \mathrm{bp}$ paired-end reads were generated from the eighteen samples via RNA-Seq. After $0.42 \%$ adaptor deletion, $1.30 \%$ lowquality read filtering and $0.001 \% \mathrm{~N}$-containing read filtering, $>98.27 \%$ of the sequences were confirmed as clean reads. Detailed information about the obtained reads is listed in Additional file 1. By anchoring the clean reads to the cotton reference genome, we obtained the expression data of 76,331 genes among the 18 samples (Additional file 2). The BLAST algorithm was then used to identify Arabidopsis thaliana transcripts to determine the functional annotations in cotton.

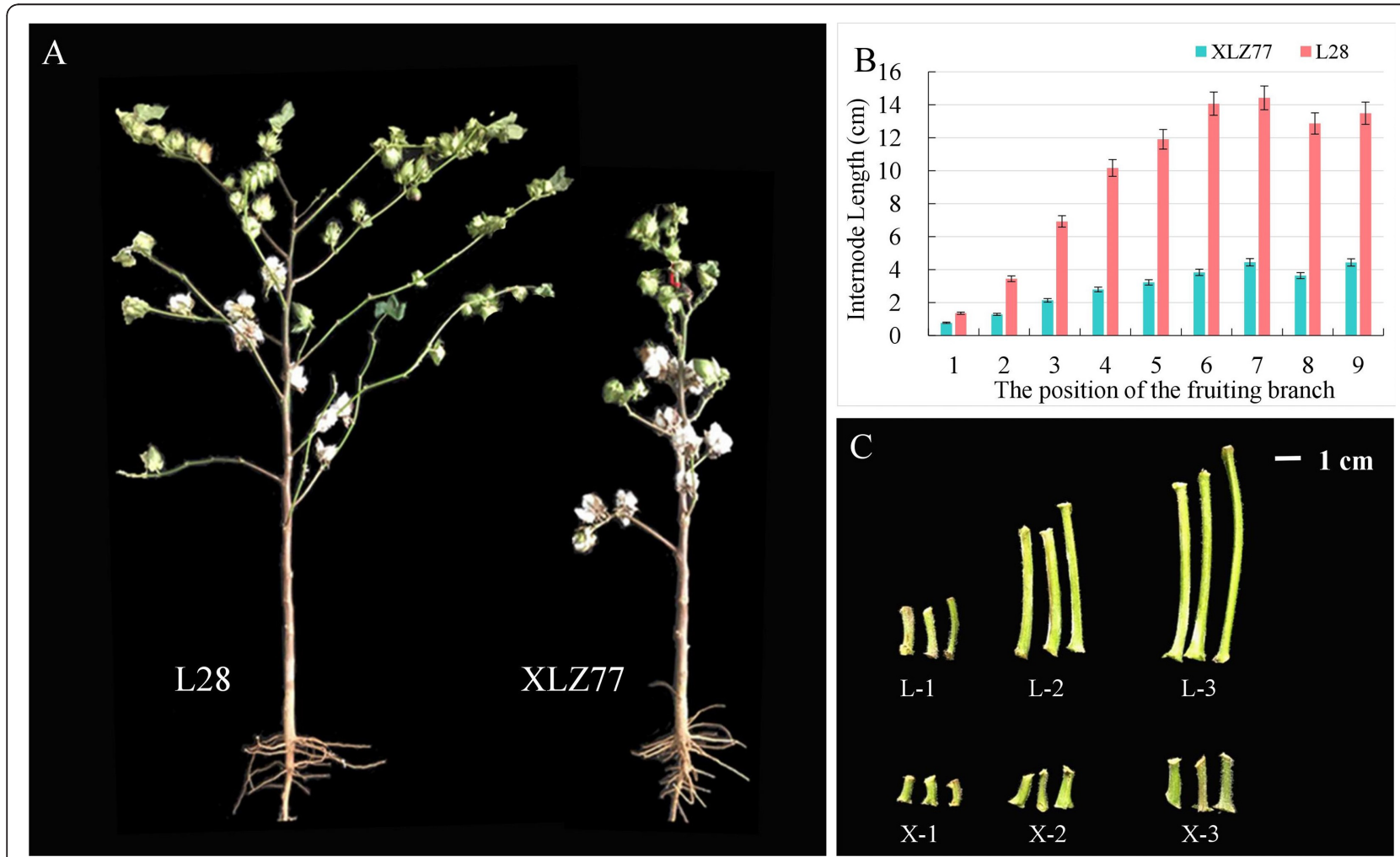

Fig. 1 Phenotypic difference between XLZ77 and L28. a. Whole-plant phenotypic differences between XLZ77 and L28. b. The first internode length of the fruiting branch of the two genotypes; the position of the fruiting branch is counted from the top of the plant. c. Sample differences between XLZ77 and L28. L, L28. X, XLZ77. The numbers represent the position of the fruiting branch 
Screening and identification of differentially expressed genes (DEGs).

To identify DEGs between the two genotypes, the edgeR package (http://www.rproject.org/) was used. We identified genes fold change (FC) was $\geq 2$ and whose false discovery rate (FDR) was $<0.05$ in a comparison as significantly differentially expressed. The number of DEGs between each pair of compared groups is shown in Additional file 3. When the different internodes of the same variety were compared, the numbers of upregulated and downregulated DEGs in L- 1 vs L-2 and in L-1 vs L-3 were nearly identical. The fewest DEGs occurred in the $\mathrm{X}-1$ vs $\mathrm{X}-2$ comparison, but in the $\mathrm{X}-1$ vs $\mathrm{X}-3$ comparison, the number of upregulated DEGs in X-1 was 1.8 times as high as that of downregulated DEGs. However, when the same internodes of the different varieties were compared, the number of upregulated DEGs in X-1 was 3.5 times as high as that of the downregulated DEGs in the X-1 vs L-1 comparison. In the X-2 vs L-2 comparison, the number of upregulated DEGs in X1 was 3.1 times as high as that of the downregulated DEGs.

\section{Kyoto encyclopedia of genes and genomes (KEGG) enrichment analysis showed that plant hormones played important roles in internode elongation of fruiting branches in cotton}

To understand the DEGs functions, KEGG pathway enrichment analysis was performed in accordance with a $p$-value of 0.05 adjusted by the FDR as the cutoff. The analysis results are shown in Additional file 4. Plant hormone signal transduction pathways were significantly enriched in the $\mathrm{X}-1$ vs $\mathrm{L}-1, \mathrm{X}-3$ vs $\mathrm{L}-3, \mathrm{~L}-1$ vs $\mathrm{L}-2$ and L-1 vs L-3 comparisons, which suggests that plant hormone signal transduction pathways may play important roles in the internode elongation of fruiting branches in cotton.

To identify the contributions of hormone-mediated transcriptional regulation to the internode elongation of fruiting branches in cotton, we mapped the DEG transcripts to eight hormone-related pathways in the Arabidopsis Hormone Database; 1009 genes associated with various aspects of hormone homeostasis were enriched (Additional file 5). The genes whose expression significantly differed the most were related to auxin, ET, CK and jasmonic acid (JA).

Auxin influx carrier (AUX1) is a high-affinity indole-3acetic acid (IAA) importer. In the present study, a total of 18 AUX1-related genes were differentially expressed in the two varieties. Eleven of these genes were highly expressed in L28 (Fig. 2a). GH3 is a negative regulator of auxin signal transduction. A total of 49 DEGs between both varieties were annotated as $G H 3,20$ of which were highly expressed in XLZ77 (Fig. 2b); we excluded 29 genes with FPKM $<1$.
In the ET signal transduction pathway, a total of 7 DEGs between the varieties were annotated as ethyleneinsensitive protein (EIN2), 20 DEGs were annotated as EIN3 and 35 DEGs were annotated as ethylene response factor $(E R F) 1 / 2$. All of the EIN2-related and 14 of the EIN3-related DEGs were highly expressed in XLZ77, while most of the ERF1/2-related genes were also highly expressed in XLZ77 (Fig. 2c). In addition, ACC synthase $(A C S)$ is the most important enzyme in the ET synthesis pathway. There were 26 DEGs related to ACS between the two varieties, excluding unexpressed genes, 12 of which were highly expressed in XLZ77 (Fig. 2d). All of the above results indicate that the genes involved in ET synthesis and signal transduction were highly expressed in XLZ77.

Jasmonate synthetase (JAR1), insensitive mutant of coronatine, jasmonate SCF-COI1 receptor complex (COI1) and $M Y C 2$ are all positive regulators of the JA signal transduction pathway. In our results, a total of 8 DEGs between the varieties were annotated as JAR1, 10 DEGs were annotated as COI1 and 13 DEGs were annotated as $M Y C 2$. The majority of these genes were highly expressed in XLZ77 (Fig. 2e), and we excluded the genes with FPKM $<1$ and newly annotated genes.

Degradation of the GK plant hormones is catalyzed by the cytokinin oxidase/dehydrogenase $(C K X)$ enzymes. In the present study, 27 DEGs related to $C K X$ were significantly enriched between the two varieties, the majority of which were highly expressed in XLZ77 (Fig. 2f).

Endogenous hormone contents in the two genotypes.

To compare the roles of endogenous hormones in internode elongation between different internodes of cotton fruiting branches, the contents of IAA, zeatin (ZT) and JA were measured. Independent samples collected from the first internodes of the first, second and third branches from the top were used for endogenous hormone measurements. As shown in Fig. 3, the content of IAA between the two varieties significantly differed at the inverted 1 and 3 internodes. The content of JA in the inverted 3 internode of XLZ77 was significantly higher than that in L28 and reached $107.75 \mathrm{ng} / \mathrm{g}$. Furthermore, compared with that in XLZ77, ZT content in L28 increased by $0.64 \mathrm{ng} / \mathrm{g}$ and 1.26 $\mathrm{ng} / \mathrm{g}$ in inverted 1 and 3 internodes, respectively; these differences were significant. In addition, we measured the content of the ET precursor ACC, which was higher in all three internodes of XLZ77 relative to L28, and the difference was significant at the inverted 2 internode.

\section{Validation of genes related to plant hormone signal transduction by qRT-PCR}

To further verify the correctness of the RNA-Seq analysis results, twelve genes whose expression was relatively high were selected for real-time quantitative PCR (qRT-PCR). The qRT-PCR results for these genes were highly consistent 


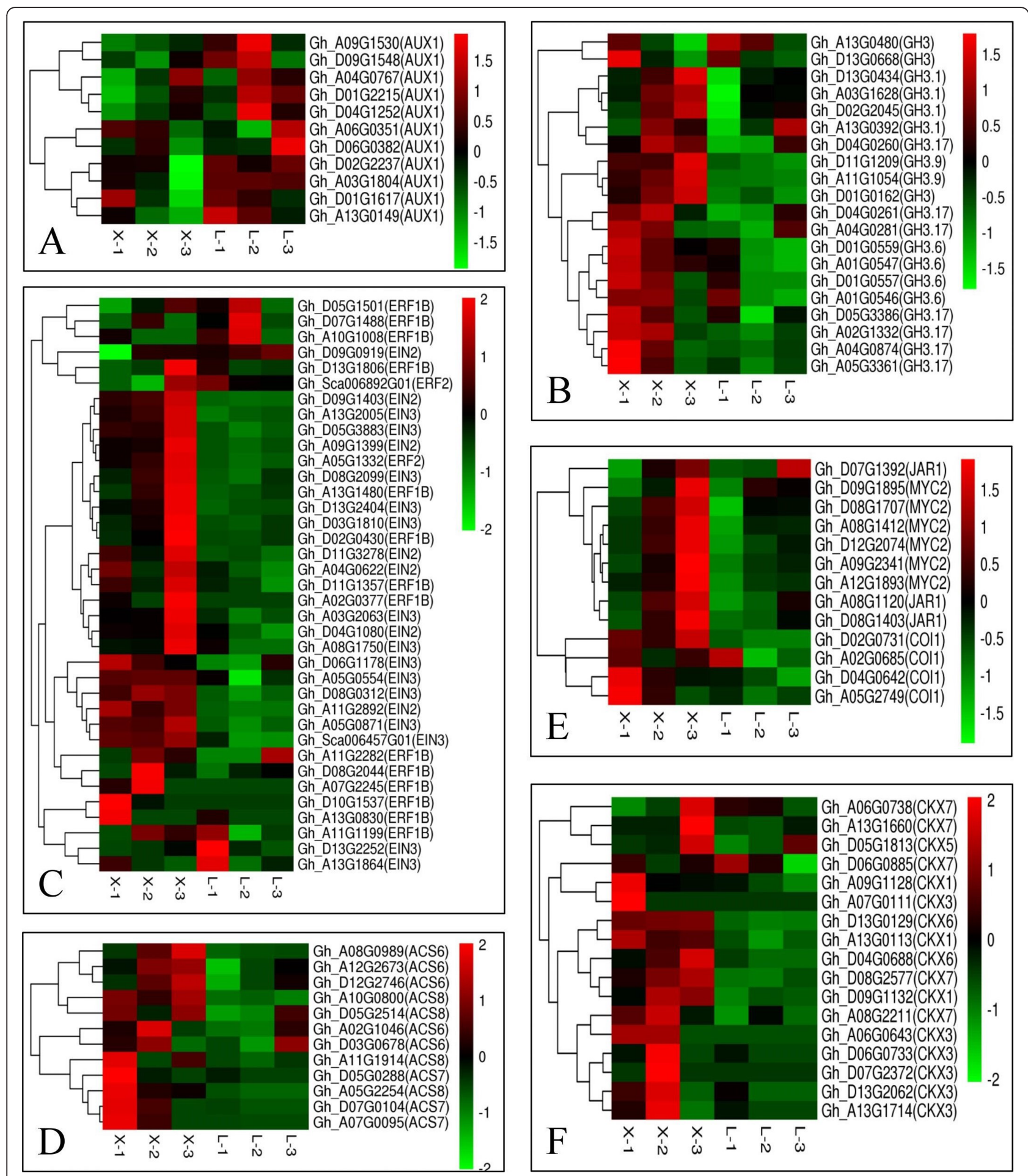

Fig. 2 Cluster heat map of plant hormone-related genes. a. AUX1; b. GH3; c. EIN2/3 and ERF1/2; d. ACS; e. JAR1, MYC2, COI1; f. CKX. The expression of all the genes listed in these maps is shown in Additional file 6

with the RNA-Seq data (Fig. 4). With the exception of AUX1, all other genes were highly expressed in the shortinternode variety XLZ77. Here, we show only nine pictures, and the other three pictures are shown in Additional file 7. The validation experiments support the accuracy of the relative values provided by the RNA-Seq analysis. 

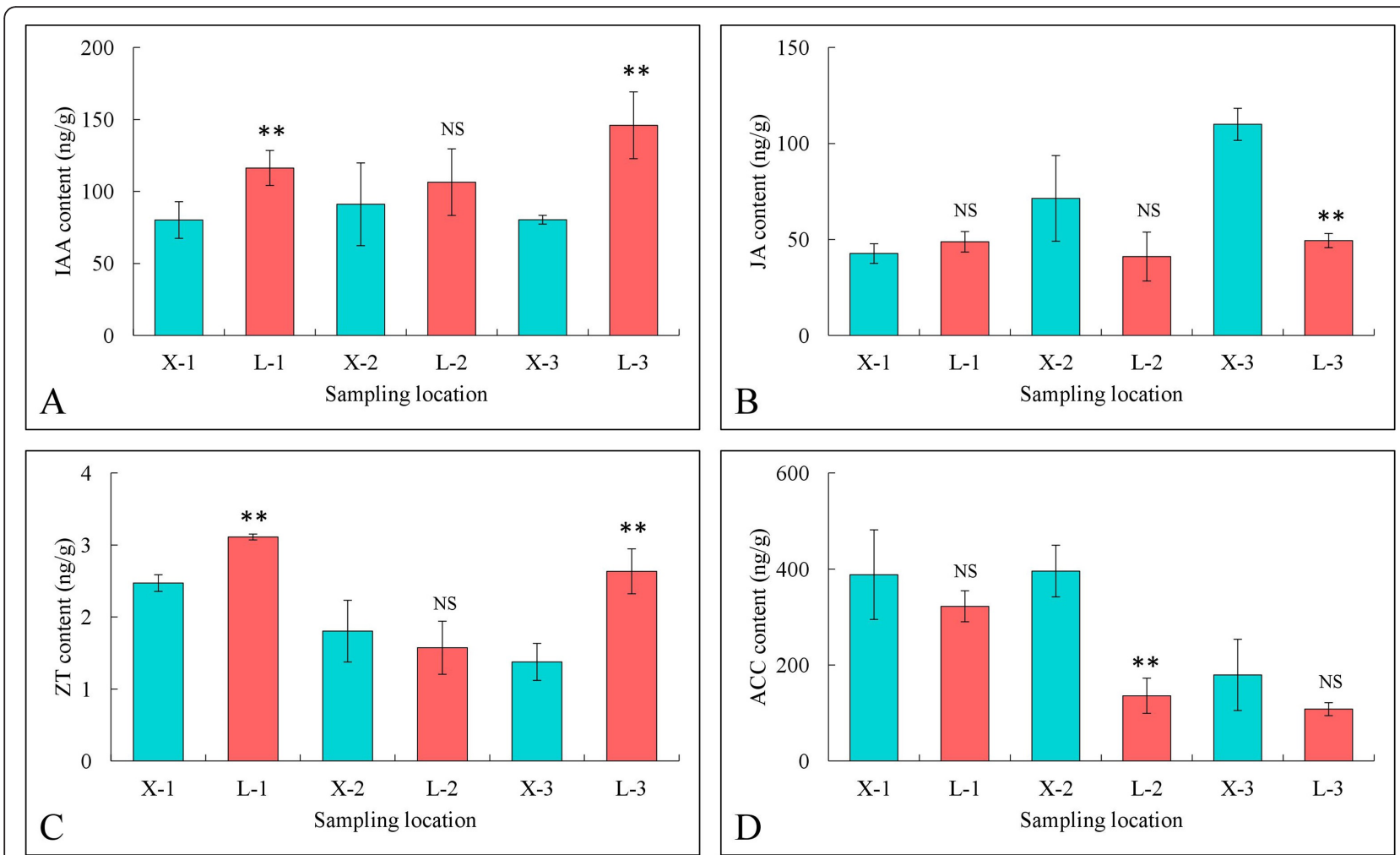

Fig. 3 Endogenous hormone contents in XLZ77 and L28. a. IAA; b. JA; c. ZT; d. ACC. The data were analyzed by three independent repeats, and standard deviations are shown with error bars. The internodes in the same position act as a comparison group. Significant differences are indicated by "*", "NS" represents no significant difference

\section{Gene ontology (GO) enrichment analyses of DEGs}

GO category enrichment analysis was performed using the DEGs identified from each comparison. Here, our analysis includes only the majority of the GO terms associated with biological processes (Additional file 8).

With respect to the X-1 vs L-1 comparison group, DEGs were significantly enriched in the GO categories of nucleosome assembly, chromatin assembly and nucleosome organization. With respect to the X-2 vs L-2 comparison group, DEGs were significantly enriched in the GO categories of nucleosome assembly, phospholipid metabolic process and membrane lipid metabolic process. In the $\mathrm{X}-3$ vs $\mathrm{L}-3$ comparison group, DEGs were significantly enriched in the $\mathrm{GO}$ categories of mitotic cell cycle process, cell cycle, cell division, the secondary metabolic process and cell wall organization. With respect to the L-1 vs L-2 comparison group, the DEGs were significantly enriched in the xyloglucan metabolic process, cell wall organization, cell wall organization or biogenesis and cell wall polysaccharide metabolic process $\mathrm{GO}$ categories. With respect to the $\mathrm{L}-1$ vs $\mathrm{L}-3$ comparison group, DEGs were also significantly enriched in the GO categories of cell wall organization or biogenesis, xylan biosynthetic process, xylan metabolic process and plant-type cell wall loosening. With respect to the X-1 vs X-2 comparison group, DEGs were significantly enriched in the GO categories of plant-type cell wall organization or biogenesis, xyloglucan metabolic process, cell wall modification and plant-type cell wall loosening. In addition, the majority of genes related to these GO categories were highly expressed in X-2. However, with respect to the X-1 vs X-3 comparison group, DEGs were significantly enriched in the GO categories of cell cycle, regulation of cell cycle, cell division, cell wall biogenesis and secondary metabolic process.

\section{Cluster analysis of DEGs and GO category enrichment analysis of each module}

In accordance with the condition of FPKM $\geq 10$ for at least one sample, we screened 7330 DEGs in the comparison groups $\mathrm{X}-1$ vs $\mathrm{L}-1, \mathrm{X}-2$ vs $\mathrm{L}-2, \mathrm{X}-3$ vs $\mathrm{L}-3$, etc., for cluster analysis (Fig. 5). Based on the differences in the expression trends shown in the cluster heat map, the 7330 DEGs were divided into 10 modules, each with a unique expression trend. GO category enrichment analysis was performed on the DEGs in each module. According to the enrichment analysis and gene annotation results, we identified important GO terms for each module. The number of genes in each module and information for selected important GO terms are shown in 

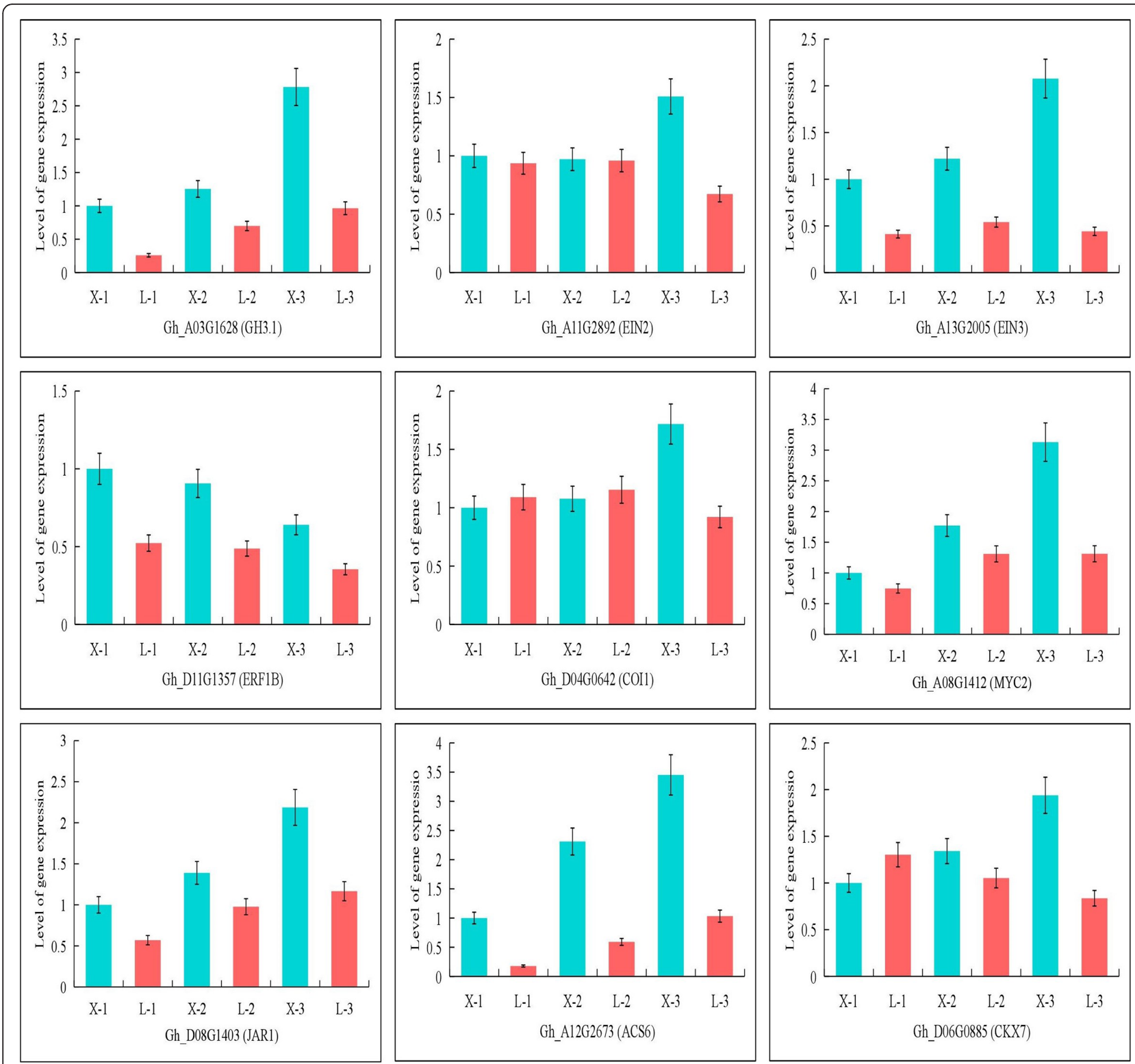

Fig. 4 RT-PCR validation of genes related to plant hormone signal transduction. Expression levels of 12 plant hormone signal transduction-related genes in the two varieties were validated by qRT-PCR. All data are based on the analysis of three independent biological repeats

Table 1, and the expression of the genes in each module is shown in Additional file 9. Here, we analyzed only the majority of GO terms based on biological processes (Additional file 10).

With respect to module 1 , the expression of genes was higher in XLZ77 than in L28. The DEGs were significantly enriched in the lipid metabolic process GO category. The genes Gh_A03G0871 and Gh_D02G1254 were mapped to $A T 1 G 14290$, which encodes sphingoid base hydroxylase $2(\mathrm{SBH} 2)$ and is involved in sphingolipid trihydroxy long-chain base (4-hydroxysphinganine) biosynthesis.
With respect to module 2, the gene expression in X-2 and X-3 was higher in XLZ77 than in L28. DEGs were significantly enriched in the GO categories of cellular protein complex disassembly, protein complex disassembly, cell wall biogenesis and sphingolipid metabolic process. The gene Gh_D09G0602 was significantly enriched in the above GO categories, was expressed more than the other genes, it was mapped to AT3G16630, which encodes KINESIN-13A. There are two important genes in the metabolic process of sphingolipids category: Gh_D02G1253 and Gh_A11G3137. The gene Gh_D02G1253 was mapped to AT1G14290, which encodes the sphingosine hydroxylase 


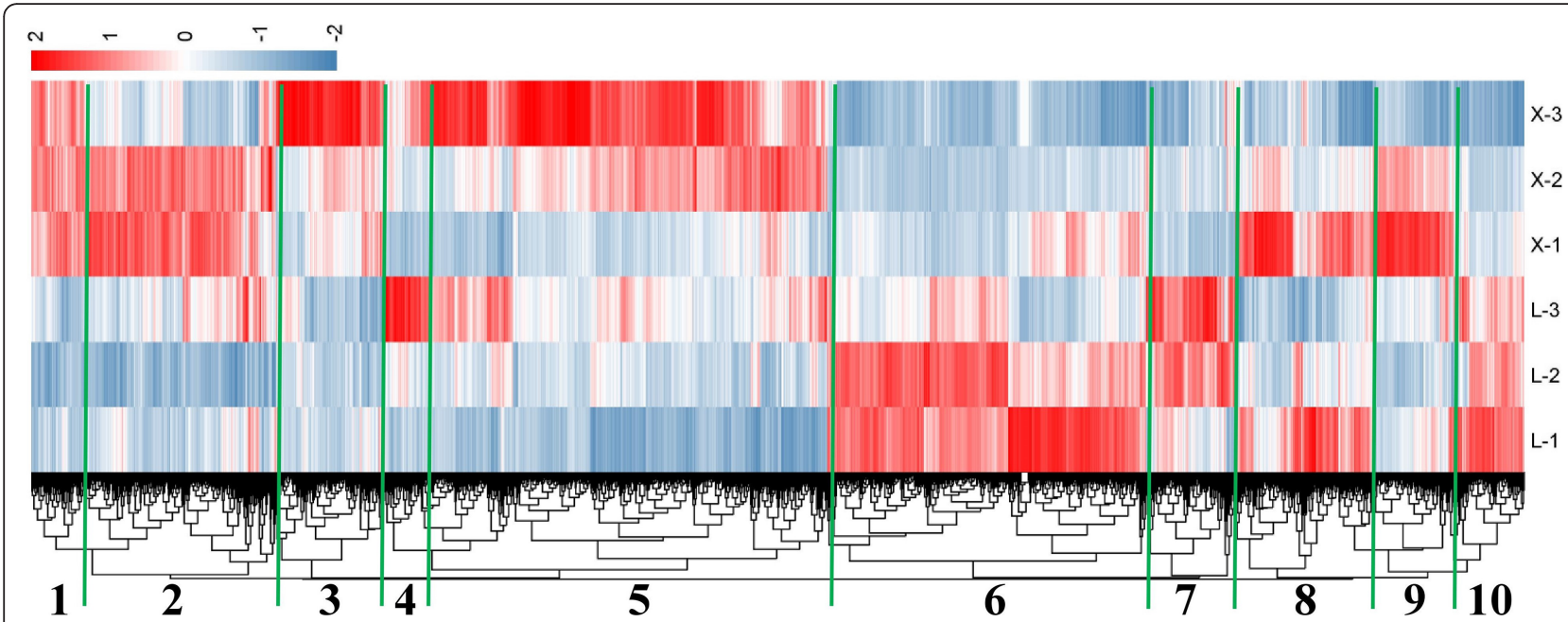

Fig. 5 Cluster analysis of 7330 DEGs. According to the gene expression trends, the cluster heat map was divided into 10 modules to further explore the biological significance of each module. The number in the figure represents the name of each module

SBH2. The gene Gh_A11G3137 was mapped to AT5G10480, which encodes the protein tyrosine phosphatase PAS2.

With respect to module 3, gene expression was highest in X-3. The first GO category enriched was the lignin biosynthetic pathway, which included 14 genes: Gh_ $D 11 G 2151$ and Gh_D12G0788 were mapped to $A T 2 G 22420$, which encodes a peroxidase superfamily protein (POX); Gh_D10G2466 and XLOC_076267 were mapped to $A T 2 G 38080$, which encodes a laccase/diphenol oxidase family protein (LAC4); Gh_A10G1518 and Gh_D10G1769 were mapped to chitinase-like protein 2 (CTL2); Gh_A04G1032 was mapped to AT4G34050, which encodes an S-adenosyl-L-methionine-dependent methyltransferase superfamily protein (CCOAOMT1); Gh_A05G1579 was mapped to AT4G39330, which encodes cinnamyl alcohol dehydrogenase $9(C A D)$; and Gh_A11G1648, Gh_D11G1805 and Gh_Sca004990G01 were mapped to AT4G36220, which encodes ferulic acid 5-hydroxylase $1(F 5 H)$. All of the above proteins (enzymes) are important in the biosynthesis of lignin.

Regarding module 4, the expression of genes was highest in L-3. The first GO category enriched was phenylpropanoid catabolic process, which contrasts with the GO category results obtained for module 3 . A total of 13 genes were enriched in this module, and all of these genes were related to LAC: LAC2,LAC4, LAC5 and $L A C 17$. The results showed that lignin was degraded more in L28 than in XLZ77; but decomposed and was metabolized to a lesser degree in the latter. This finding explains the differences in internode length.

With respect to module 5 , the majority of genes were highly expressed in X-3. The DEGs were significantly enriched in the ET-activated signaling pathway GO category. A total of 76 genes were enriched in this module;

Table 1 Number of genes in each module and related GO term information

\begin{tabular}{lllll}
\hline Module Name & Number of Genes & Related GO ID & Description & Number of GO Genes \\
\hline Module1 & 263 & GO:0006629 & lipid metabolic process & 23 \\
Module2 & 987 & GO:0043624 & cellular protein complex disassembly & 14 \\
& & GO:0006665 & sphingolipid metabolic process & 8 \\
Module3 & 502 & GO:0009809 & lignin biosynthetic process & 14 \\
Module4 & 175 & GO:0046271 & phenylpropanoid catabolic process & 13 \\
Module5 & 2003 & GO:0009873 & ethylene-activated signaling pathway & 76 \\
Module6 & 1533 & GO:0006334 & nucleosome assembly & 28 \\
Module7 & 454 & GO:0071555 & cell wall organization & 51 \\
Module8 & 633 & - & - & - \\
Module9 & 440 & - & - & - \\
Module10 & 340 & GO:0010410 & hemicellulose metabolic process & 10 \\
\hline
\end{tabular}


most of these genes were related to ERFs. In addition, 8 genes in the pathway were mapped to AT3G51550, which encodes a FERONIA protein, a member of a family of receptor-like protein kinases.

Regarding module 6, gene expression in the three internodes was higher in L28 than in XLZ77. Moreover, the expression of these genes decreased as the internodes of fruiting branches elongated for the same variety. The DEGs were significantly enriched in the nucleosome assembly GO category. A total of 28 genes were enriched in this module; 19 of these genes were mapped to AT5G65360, which encodes a histone superfamily protein. In addition, most of the GO categories in module 6 were related to nucleosome assembly, chromatin assembly, DNA replication, mitosis, etc. It can be inferred that the genes were mainly enriched in the pathway of cell division.

With respect to module 7 , the gene expression of the three internodes was higher in L28 than in XLZ77. In addition, the expression of these genes increased in L28 as the internodes of the fruiting branches elongated. The first GO category enriched was cell wall organization, which included 51 genes, 9 of which were mapped to EXP-related genes encoding expansins. In our samples, 107 EXP-related genes were screened from among all DEGs, and the expression of the majority of these genes was higher in L28 than in XLZ77. In addition, three genes were mapped to the AT1G75500 gene, which encodes the WALLS ARE THIN 1 (WAT1) gene.

With respect to module 10 , gene expression in the three internodes was higher in L28 than in XLZ77. The expression of most of these genes was relatively high in L-1. DEGs were significantly enriched in the hemicellulose metabolic process GO category. A total of 10 genes were enriched in this category; 8 of the genes were mapped to xyloglucan endotransglucosylase/hydrolase (XTH)-related genes. Three genes mapped to AT4G03210, which encodes XTH9. It can be inferred that the high expression of $X T H$ genes in L28 leads to cell expansion and elongation.

Important genes and their predicted functions in the internode elongation of fruiting branches in cotton are shown in Table 2. These genes could be used to genetically improve internode length in cotton.

\section{Cluster analyses of differentially expressed TFs}

TFs are key regulatory proteins that are essential for the regulation of gene expression. There were significant differences in the expression of 2067 TFs between the two varieties (Additional file 11). The WRKY, ERF and $b H L H$ families were the top three largest families of TFs. As shown in Table 3, 224 genes in the WRKY family, 256 genes in the $b H L H$ family and 399 genes in the ERF family were enriched between the two varieties; most of them were upregulated in XLZ77. The high expression of these TF families in XLZ77 could be the main reason for the shorter internodes of the fruiting branches.

\section{Discussion \\ Regulation of plant hormone involved in the internode elongation of fruiting branches in cotton}

Higher plants develop their plant architecture by regulating the activity of the apical meristem and side meristem. The activity of the meristems is regulated by environmental signals, developmental stages and genetic factors. The comprehensive regulation of these factors confers developmental plasticity to plants and their adaptability to the environment. Plant hormones are at the center of a network system that governs many regulatory signals. These hormones play an important role in plant architecture formation [26]. Specifically, the phytohormones auxin and CK can promote cell expansion and division, whereas ET and JA inhibit organ growth by affecting cell expansion [27].

The plant hormone IAA controls growth and developmental responses throughout the life of a plant; specifically, IAA is involved in cell expansion and division, tissue differentiation, organ development and a variety of physiological responses [28]. The content and distribution of auxin play important roles in plant morphogenesis [29]. Auxin is a weak acid that protonates in a low-pH environment outside the cell and enters the cell by infiltration or mediation by an input vector. After auxin enters a cell, the increased $\mathrm{pH}$ of the cytoplasm causes the auxin to remain in the cell in an ionic state, whereas auxin is transported out of the cell depending on specific output carrier. The AUX1 gene encodes a component of the auxin influx carrier, and mutations within AUX1 selectively impair the action of auxins that require carrier-mediated uptake [30]. The accumulation of auxin in the root apex clearly decreases when $A U X 1$ is mutated [31]. The Gretchen Hagen-3 (GH3) gene family encodes a class of luciferase [32] that can catalyze the formation of an inactive form of auxin by binding IAA and amino acid molecules in vitro [33]; this luciferase is a negative regulator of auxin signal transduction. Overexpression of GH3.2, GH3.5 or GH3.6 can result in plant dwarfism, inhibition of hypocotyl elongation of seedlings, reduction in lateral roots, loss of apical dominance and endogenous auxin deficiency [34]. Our RNASeq and qRT-PCR results indicate that the expression levels of the key genes related to IAA signal transduction, including $A U X 1$, were significantly upregulated in L28, and the expression levels of the GH3 family protein genes were significantly upregulated in XLZ77. These findings indicate that auxin signal transduction is positively regulated in L28 but negatively regulated in XLZ77. Furthermore, IAA content is higher in L28 than in XLZ77. Together, these results show that auxin 
Table 2 Important genes and their predicted functions in the internode elongation of fruiting branches in cotton

\begin{tabular}{|c|c|c|c|c|c|c|c|c|c|}
\hline Gene ID & L-1_fpkm & L-2_fpkm & L-3_fpkm & X-1_fpkm & X-2_fpkm & X-3_fpkm & Description & Predicted Function & Reference \\
\hline Gh_A03G0871 & 140.59 & 123.31 & 174.71 & 288.19 & 307.84 & 312.05 & $\begin{array}{l}\text { Sphingoid base } \\
\text { hydroxylase } 2\end{array}$ & $\begin{array}{l}\text { Inhibition of growth, } \\
\text { Promote apoptosis }\end{array}$ & $\begin{array}{l}\text { Chen M et al., } \\
2008 \text { [13] }\end{array}$ \\
\hline Gh_D02G1254 & 51.05 & 42.47 & 73.17 & 193.67 & 193.92 & 168.60 & $\begin{array}{l}\text { Sphingoid base } \\
\text { hydroxylase } 2\end{array}$ & $\begin{array}{l}\text { Inhibition of growth, } \\
\text { Promote apoptosis }\end{array}$ & $\begin{array}{l}\text { Chen M et al., } \\
2008 \text { [13] }\end{array}$ \\
\hline Gh_D02G1253 & 26.06 & 4.56 & 3.80 & 64.51 & 24.95 & 22.93 & $\begin{array}{l}\text { Sphingoid base } \\
\text { hydroxylase } 2\end{array}$ & $\begin{array}{l}\text { Inhibition of growth, } \\
\text { Promote apoptosis }\end{array}$ & $\begin{array}{l}\text { Chen M et al., } \\
2008 \text { [13] }\end{array}$ \\
\hline Gh_D09G0602 & 56.28 & 47.55 & 51.27 & 109.19 & 97.56 & 71.71 & Kinase-13A & $\begin{array}{l}\text { Inhibition of } \\
\text { cell expansion }\end{array}$ & $\begin{array}{l}\text { Fujikura U } \\
\text { et al., } 2014 \text { [14] }\end{array}$ \\
\hline Gh_D09G0602 & 56.28 & 47.55 & 51.27 & 109.19 & 97.56 & 71.71 & Kinase-13A & $\begin{array}{l}\text { Inhibition of } \\
\text { cell cell size }\end{array}$ & $\begin{array}{l}\text { Li YJ et al., } \\
2017 \text { [15] }\end{array}$ \\
\hline Gh_A11G3137 & 4.98 & 2.37 & 7.81 & 10.01 & 10.12 & 3.79 & $\begin{array}{l}\text { Protein-tyrosine } \\
\text { phosphatase-like, PTPLA }\end{array}$ & $\begin{array}{l}\text { Inhibition of } \\
\text { cell division }\end{array}$ & $\begin{array}{l}\text { Bach L et al., } \\
2008[16]\end{array}$ \\
\hline Gh_A05G1579 & 23.01 & 28.32 & 29.73 & 24.85 & 28.62 & 57.19 & $\begin{array}{l}\text { Cinnamyl alcohol } \\
\text { dehydrogenase } 9\end{array}$ & Lignin accumulation & $\begin{array}{l}\text { Mansell RL } \\
\text { et al., } 2014 \text { [17] }\end{array}$ \\
\hline Gh_A10G1518 & 14.25 & 16.39 & 79.99 & 12.18 & 20.41 & 209.74 & Chitinase-like protein 2 & $\begin{array}{l}\text { Accelerate secondary } \\
\text { metabolism }\end{array}$ & $\begin{array}{l}\text { Hossain MA } \\
\text { et al., } 2010 \text { [18] }\end{array}$ \\
\hline Gh_D10G1769 & 11.60 & 13.33 & 67.11 & 7.79 & 14.97 & 144.79 & Chitinase-like protein 2 & $\begin{array}{l}\text { Accelerate secondary } \\
\text { metabolism }\end{array}$ & $\begin{array}{l}\text { Hossain MA } \\
\text { et al., } 2010 \text { [18] }\end{array}$ \\
\hline Gh_A11G2936 & 14.46 & 20.28 & 55.22 & 7.95 & 9.54 & 40.63 & $\begin{array}{l}\text { Laccase/diphenol } \\
\text { oxidase family protein }\end{array}$ & $\begin{array}{l}\text { Promotion of lignin } \\
\text { decomposition }\end{array}$ & $\begin{array}{l}\text { Berthet S et al., } \\
2011 \text { [19] }\end{array}$ \\
\hline Gh_D03G1128 & 19.76 & 29.29 & 52.91 & 20.38 & 28.83 & 47.27 & $\begin{array}{l}\text { Laccase/diphenol } \\
\text { oxidase family protein }\end{array}$ & $\begin{array}{l}\text { Promotion of lignin } \\
\text { decomposition }\end{array}$ & $\begin{array}{l}\text { Zhao Q et al., } \\
2013 \text { [20] }\end{array}$ \\
\hline Gh_D09G2057 & 21.45 & 62.35 & 73.01 & 33.54 & 70.74 & 107.94 & $\begin{array}{l}\text { Malectin/receptor-like } \\
\text { protein Kinase family } \\
\text { protein }\end{array}$ & Protoplast alkalization & $\begin{array}{l}\text { Barbez E et al., } \\
2017 \text { [21] }\end{array}$ \\
\hline Gh_D10G0981 & 237.30 & 215.92 & 111.36 & 116.78 & 90.66 & 36.42 & $\begin{array}{l}\text { Histone superfamily } \\
\text { protein }\end{array}$ & $\begin{array}{l}\text { Promoting cell } \\
\text { division }\end{array}$ & $\begin{array}{l}\text { Günesdogan } U \\
\text { et al., } 2014 \text { [22] }\end{array}$ \\
\hline Gh_A08G2114 & 202.08 & 170.28 & 81.50 & 94.56 & 62.85 & 30.06 & $\begin{array}{l}\text { Histone superfamily } \\
\text { protein }\end{array}$ & $\begin{array}{l}\text { Promoting cell } \\
\text { proliferation }\end{array}$ & $\begin{array}{l}\text { Günesdogan U } \\
\text { et al., } 2014 \text { [22] }\end{array}$ \\
\hline Gh_A13G0050 & 127.76 & 214.03 & 257.34 & 121.15 & 156.57 & 118.64 & Expansin A8 & $\begin{array}{l}\text { Promote cell } \\
\text { loosening and } \\
\text { expansion }\end{array}$ & $\begin{array}{l}\text { Nardi CF et al., } \\
2014 \text { [23] }\end{array}$ \\
\hline Gh_D13G0060 & 196.61 & 288.97 & 352.52 & 199.21 & 232.59 & 172.40 & Expansin A8 & $\begin{array}{l}\text { Promote cell } \\
\text { loosening and } \\
\text { expansion }\end{array}$ & $\begin{array}{l}\text { Nardi CF et al., } \\
2014 \text { [23] }\end{array}$ \\
\hline Gh_D01G0964 & 47.14 & 51.81 & 75.14 & 36.00 & 37.19 & 32.03 & Walls Are Thin 1 & $\begin{array}{l}\text { Promoting cell } \\
\text { elongation }\end{array}$ & $\begin{array}{l}\text { Ranocha P } \\
\text { et al., } 2010 \text { [24] }\end{array}$ \\
\hline Gh_A01G0922 & 36.58 & 39.66 & 58.01 & 24.81 & 25.32 & 28.10 & Walls Are Thin 1 & $\begin{array}{l}\text { Promoting cell } \\
\text { elongation }\end{array}$ & $\begin{array}{l}\text { Ranocha P } \\
\text { et al., } 2010 \text { [24] }\end{array}$ \\
\hline Gh_A03G1432 & 102.22 & 86.74 & 92.84 & 53.86 & 58.35 & 44.55 & $\begin{array}{l}\text { Xyloglucan } \\
\text { endotransglucosylase } \\
\text { /hydrolase } 9\end{array}$ & $\begin{array}{l}\text { Promoting cell } \\
\text { proliferation and } \\
\text { elongation }\end{array}$ & $\begin{array}{l}\text { Shin YK et al., } \\
2006 \text { [25] }\end{array}$ \\
\hline Gh_A13G0500 & 39.81 & 26.30 & 26.26 & 13.99 & 14.66 & 12.00 & $\begin{array}{l}\text { Xyloglucan } \\
\text { endotransglucosylase/ } \\
\text { hydrolase } 9\end{array}$ & $\begin{array}{l}\text { Promoting cell } \\
\text { proliferation and } \\
\text { elongation }\end{array}$ & $\begin{array}{l}\text { Shin YK et al., } \\
2006 \text { [25] }\end{array}$ \\
\hline
\end{tabular}

Table 3 Number of TFs

\begin{tabular}{llll}
\hline TF & Number & Upregulated & Downregulated \\
\hline bHLH & 256 & 158 & 98 \\
WRKY & 224 & 176 & 48 \\
ERF & 399 & 230 & 169 \\
\hline
\end{tabular}

promotes the elongation of fruiting branches in cotton. Therefore, we predicted that IAA, when maintained at a certain level and experiencing upregulated signaling, may be a hormone trigger of internode elongation.

The phytohormone ET plays roles in various physiological processes throughout the life cycle of a plant [35]. Ethephon has highly significant effects on plant height [36], ear height [37, 38] and internode length 
[39]. Reduced plant height might be due to decreased internode length in response to the application of ethephon [40]. Moreover, elevated tissue ET concentrations inhibit longitudinal cell extension and thus stem growth [41, 42]. ET inhibits the elongation of maize internodes by inhibiting the longitudinal elongation of cells [43]. ET signal transduction supposedly follows a "linear" pathway, with membrane-bound receptors at the beginning, multiple positive and negative regulators in between, and TFs at the end of the chain [44]. EIN2 is a positive regulator of the pathway, which plays a major role in the ET response [45]. Members of the EIN3 family are involved in a regulatory cascade and stimulate the transcription of other TFs such as ERF1 [46], which is a member of the ERF family of TFs [47]. These TFs have been shown to act as activators or repressors of additional downstream ET-responsive genes [48]. Our RNASeq and qRT-PCR results indicate that the genes related to EIN2, EIN3 and ERF1/2 were significantly highly expressed in XLZ77. This finding indicates that ET signal transduction is positively regulated in XLZ77. In addition, the content of ACC (the precursor of ET) in XLZ77 is higher than that in L28. Together, these data suggest that ET may act as a negative regulator of the internode elongation of fruiting branches in cotton.

The phytohormone JA plays essential roles in plant growth and development [49]. Methyl jasmonate (MeJA) inhibits root growth in some plant species. High concentrations of JA $(25 \mu \mathrm{mol} / \mathrm{L})$ can also inhibit plant growth [50]. JA inhibits the expression of cell cycle-related proteins and thus inhibits cell division [51]. JA inhibits the growth of the main roots of Arabidopsis thaliana by inhibiting cell division activity of the root meristem [52]. Our RNA-Seq and qRT-PCR results showed that positively regulated factors of JA signal transduction, including $J A R 1, C O I 1$ and $M Y C 2$, were significantly upregulated in XLZ77. This indicates that JA signal transduction is positively regulated in XLZ77 but negatively regulated in L28. Furthermore, the JA content in XLZ77 was higher than that in L28. Together, these results indicate that JA can inhibit the internode elongation of fruiting branches in cotton.

CKs affect many processes in plants, the most important of which are probably cell division and proliferation in the SAM, which are responsible for the production of all aboveground organs $[53,54]$. Within the context of plant development, the CK phytohormone play key regulatory roles in the meristems (stem cell centers) and generally positively regulate the SAM by stimulating cell division [55]. CK oxidative decomposition catalyzed by $C K X$ is an important mechanism for regulating the dynamic balance of CK content [56]. Our RNA-Seq and qRT-PCR results indicate that the expression of $C K X$-related genes (CK inactivating genes) was higher in XLZ77 than in L28. Because of the low level of CKs, the cell division process was suppressed in XLZ77. Furthermore, the content of ZT was higher in L28 than in XLZ77. Taken together, these data suggested that CK may act as a positive regulator in the internode elongation of fruiting branches in cotton.

In summary, we propose a hypothetical model to explain the role of phytohormones in the internode elongation of fruiting branches in cotton (Fig. 6). In XLZ77, upregulated ET and JA can inhibited the elongation and division of cells, resulting in fewer cells and a slow increase in size, thus leading to a relatively short internode length of the fruiting branches. However, the content and signal transduction of both auxin and CK were downregulated, which resulted in slowed cell elongation, expansion and cell division; thus, the number and volume of cells increased slowly, eventually inhibiting the internode elongation of the cotton fruiting branches.

\section{Regulatory role of TFs in the internode elongation of cotton fruiting branches}

TFs are regulatory proteins that can activate or repress the transcription of multiple target genes in living organisms, and TF-mediated gene expression regulatory networks play important roles in plant growth and development. Plant growth and development can be regulated by regulating a series of TFs. In the present study, 2067 TFs were significantly enriched among all genes between the two genotypes. Among the various TFs, the TFs WRKY, ERF and $b H L H$ constituted the top three largest families who members were active between these two genotypes. In addition, most of the TFs were significantly upregulated in XLZ77.

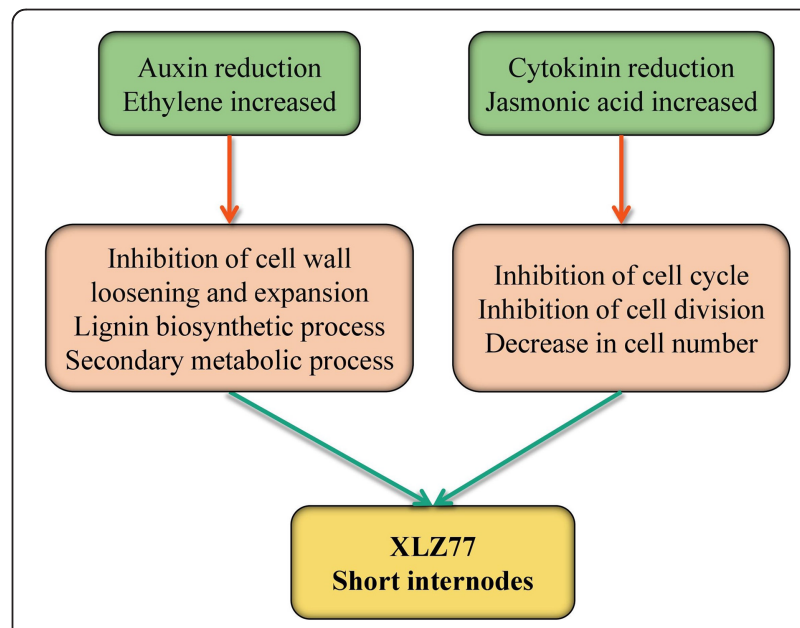

Fig. 6 Suggested model for plant hormone-mediated regulation of internode elongation in cotton 
WRKY proteins compose a large superfamily of transcriptional regulators that are involved primarily in various plant physiological programs. Members of the WRKY TF family play an indispensable role in plant root, stem and leaf formation and development. OsWRKY78 can regulate both stem elongation and seed development [57]. Similarly, AtWRKY71 regulates branching development in Arabidopsis thaliana [58]. GhWRKY15 not only contributes to the alteration of defense resistance to both viral and fungal infections but also affects plant growth and development, especially stem elongation [59]. Our results showed that most of the 224 WRKY-related genes were upregulated in XLZ77. These findings indicate that WRKY TFs may play negative regulatory roles in the internode elongation of cotton branches.

The typical biological effect of ET is the inhibition of both the elongation and growth of stems and roots and the promotion of stem and root lateral growth. The ERF family of TFs, which is present only in the plant kingdom, is characterized by the presence of a highly conserved DNA-binding domain [60] that can positively regulate the signal transduction pathway of ET. Moreover, some rice ERFs have been reported to plays roles in regulating internode elongation [61]. Another ERF gene, $S U B 1 A$, restricts plant elongation at the seedling stage during flash floods [62]. The rice $A P 2 / E R F$ protein $O S E A T B$ restricts internode elongation by downregulating a GA biosynthesis gene [63]. Our data showed that 399 genes related to ERF TFs were enriched, and approximately $2 / 3$ of these genes were highly expressed in XLZ77. Thus, ERF TFs may play a negative role in the internode elongation of fruiting branches in cotton.

bHLH TFs compose a large family within the plant genome. These TFs play important roles in plant growth and development, nutrient absorption, biosynthesis, signal transduction, etc. [64]. ILI1 and PRE1 interact with the $b H L H$ protein IBH1 (ILI1 binding $b H L H$ ), whose overexpression causes erect leaves in rice and dwarfism in Arabidopsis [65]. The LAX (OsHLH164) gene is expressed at the boundary between the SAM and the region of new meristem formation; $L A X$ genes have been identified as the main regulators of axillary meristem formation in rice [66]. Our results showed that 256 genes related to $b H L H$ TFs were significantly enriched, and approximately $3 / 4$ of these genes were highly expressed in XLZ77. These findings indicate that $b H L H$ TFs may play a negative regulatory role in fruiting branch internode elongation in cotton.

In summary, we can assume that the WRKY, bHLH and ERF TFs mainly inhibit the internode elongation of cotton fruiting branches. The upregulation of these TFs in XLZ77 may be the primary reason for the relatively short internodes in that variety. The differences in endogenous hormone content may be caused by mutations in TFs. In the future, we will attempt to locate these mutation sites by map-based cloning to further explore the mechanism of internode elongation.

\section{Conclusions}

In this study, we selected the fruiting branch internodes at three different stages from two cotton cultivars whose fruiting branch internode lengths significantly differed. A total of 76,331 genes were detected by transcriptome sequencing. The potential roles of a series of DEGs involved in the internode elongation of cotton were identified and analyzed by GO category and KEGG pathway analyses, qRT-PCR verification and hormone content determination. We found that auxin and CK are the positive regulators of internode elongation in cotton branches. In contrast, ET and JA may act as negative regulators of internode elongation in cotton branches. Furthermore, the WRKY, ERF and bHLH TFs were identified as important inhibitors of the elongation of internodes in cotton. In XLZ77 (a short-internode variety), the mass synthesis of ET and the amino acid conjugation of auxin led to the inhibition of plant cell elongation, while the increase in JA content and the degradation of CKs led to a slow rate of cell division, which eventually resulted in a phenotype that included relatively short internodes of fruiting branches. The results of this study not only provide gene resources for the genetic improvement of cotton plant architecture but also lay a foundation for improved understanding of the molecular mechanism of the internode elongation of cotton branches.

\section{Methods}

Plant material and sampling

In our study, two cotton genotypes-a short-internode cultivar (Xinluzhong77, XLZ77) and a long-internode cultivar (Lumianyan28, L28) -were used. The two genotypes were planted at the experimental station of the Institute of Cotton Research of the CAAS in Anyang City (Henan Province, China) on April 20, 2017, after which the plants were subjected to routine field management. The first internodes of the first, second and third branches from the top of the plants were collected at the cotton bud stage (July 6, 2017). A schematic diagram of the cotton sampling positions is shown in Additional file 12. Three biological replicates were included; the samples of each biological replicate were pooled from 10 plants, which were randomly selected to avoid any potential effects of position in the field. The three biological replicates were mixed together and then divided into two groups; one group was used for RNA isolation via Illumina sequencing and qRT-PCR analysis, and the other was used for endogenous hormone measurements. The samples were frozen immediately in liquid nitrogen and then stored at $-80^{\circ} \mathrm{C}$ until use. 
RNA isolation, library construction and RNA-Seq

Total RNA was extracted using a Plant RNA Kit (Omega Bio-Tek, USA) according to the manufacturer's protocol. RNA integrity and quantity were verified by RNase-free agarose gel electrophoresis and with a 2100 Bioanalyzer (Agilent Technologies, USA). Subsequent experiments were carried out with qualified RNA samples.

A sequencing library was constructed with a NEBNext1 Ultra $^{\text {тм }}$ Directional RNA Library Prep Kit for Illumina (NEB, USA) according to the manufacturer's recommendations. Briefly, the total mRNA was isolated with oligo (dT) beads. All of the mRNA was cut into short fragments (200 nt) by adding a fragmentation buffer. First-strand cDNA was generated using random hexamer-primed reverse transcription. Second-strand cDNA was then synthesized by DNA polymerase I and RNase H. Afterward, the synthesized cDNA fragments were purified and then subjected to end pairing, the addition of a single "A" base, and ligation with Illumina adapters. The ligation products were subsequently size-fractioned by agarose gel electrophoresis, after which the fragments were excised for PCR amplification. The amplified fragments were sequenced using an Illumina HiSeq ${ }^{\mathrm{Tm}} 4000$ by Gene Denovo Co. (Guangzhou, China).

\section{Sequencing analysis and differential expression analysis}

After sequencing, the reads with adapter sequences were removed. Reads with more than $10 \% \mathrm{~N}$ bases and lowquality $(\mathrm{Q} \leq 20)$ reads with more than $50 \%$ bases were then removed from each data set to gain more reliable results. The alignment software TopHat2 (v2.1.1) was used to map the reads to the Gossypium hirsutum L. genome [67]. The number of mapped clean reads for each gene was then counted and normalized into reads per kilobase per million reads (RPKM) for calculating gene expression. When comparing two groups, edgeR was used to analyze DEGs to correct for multiple testing, and the FDR was calculated to adjust the threshold of the $p$-value. Genes with a minimum 2-fold difference in expression, $|\log 2 \mathrm{FC}| \geq 1$ and FDR $\leq 0.05$ were considered DEGs.

GO classification was performed via WEGO (http:// wego.genomics.org.cn/cgi-bin/wego/index.pl), and the GO categorization results were expressed as 3 independent hierarchies for molecular function, biological process and cellular component. For each KEGG pathway, the numbers of DEGs were compared to the entire reference gene set by hypergeometric tests to determine the pathways enriched for differentially regulated genes. The $p$-values of the GO and KEGG enrichment analyses were adjusted using the Bonferroni correction, and a corrected p-value $\leq 0.05$ was chosen as the threshold value for determining significantly enriched GO terms. With respect to KEGG enrichment analysis, pathways with an FDR value $\leq 0.05$ were considered enriched.

\section{Real-time PCR validation}

Twelve genes that exhibited different expression patterns as revealed by RNA-Seq were selected for validation by qRT-PCR. Total RNA was extracted from the same samples that were used for sequencing. First-strand cDNA was synthesized using a Primer Script RT Reagent Kit (Takara Bio Inc., Shiga, Japan). The primer sequences used were designed with Primer Premier 5.0 software (Premier Biosoft International, Palo Alto, CA, USA) and synthesized by Sangon Biotech (Shanghai) Co., Ltd. The specific primers for the selected genes and the internal control gene $(U B Q)$ are listed in Additional file 13. qRTPCR was performed on a 7500 Fast Real-Time PCR System (Applied Biosystems, StepOnePlus, USA) using BCS $^{\oplus}$ Wiz Universal SYBR Green qPCR Master Mix (Transgen Biotech, Beijing, China). The cotton $U B Q$ gene was used as an internal standard to calculate relative fold differences based on comparative cycle threshold $\left(2^{-\Delta \Delta C t}\right)$ values [68]. Then, $d \mathrm{dH}_{2} \mathrm{O}$ was then used as a nontemplate control. The qRT-PCR procedure was as follows: $2 \mu \mathrm{L}$ of a $1 / 8$ dilution of $c D N A$ in $\mathrm{H}_{2} \mathrm{O}$ was added to $10 \mu \mathrm{L}$ of SYBR Green PCR Master Mix; $0.4 \mu \mathrm{L}$ of each primer and $7.2 \mu \mathrm{L}$ of $\mathrm{H}_{2} \mathrm{O}$ were then added, and the final volume was brought to $20 \mu \mathrm{L}$. The qPCR program was as follows: $50^{\circ}$ $\mathrm{C}$ for $2 \mathrm{~min}$; $95^{\circ} \mathrm{C}$ for $10 \mathrm{~min}$; followed by 40 cycles of $95^{\circ}$ $\mathrm{C}$ for $30 \mathrm{~s}, 56^{\circ} \mathrm{C}$ for $30 \mathrm{~s}$, and $72{ }^{\circ} \mathrm{C}$ for $30 \mathrm{~s}$ in 96 -well optical reaction plates. Each real-time PCR was performed three times.

\section{Measurements of various hormones}

To analyze the endogenous hormone contents, independent samples from XLZ77 and L28 were harvested, immediately frozen in liquid nitrogen and then stored at $-80^{\circ} \mathrm{C}$ for further determination. Each sample was prepared in triplicate. Endogenous IAA, ZT, JA and ACC contents were determined using an ultra-performance liquid chromatography-electrospray ionization-tandem mass spectrometry (UPLC-ESI-MS/MS) system [69].

\section{Statistical analysis}

Significant differences between values were determined using one-way ANOVA with the Tukey test at a significance level of $\alpha=0.01$ in Excel software. All expression analyses were performed for three biological replicates. All reported values represent the arithmetic averages of three replicates, and the data are expressed as the mean plus or minus standard deviation (means $\pm \mathrm{SD}$ ). 


\section{Additional files}

Additional file 1: Detailed information on the obtained reads via RNA-Seq. (XLS $20 \mathrm{~kb}$ )

Additional file 2: Expression of all genes in the 18 samples. (XLS $64722 \mathrm{~kb}$ ) Additional file 3: Detailed information on the number of DEGs between each pair of compared groups. (JPG $275 \mathrm{~kb}$ )

Additional file 4: List of KEGG pathways enriched in each comparison. (XLS 163 kb)

Additional file 5: List of genes associated with various aspects of hormone homeostasis. (XLS 1631 kb)

Additional file 6: List of genes related to hormone signal transduction in Fig. 2. (XLS 305 kb)

Additional file 7: Additional figure showing the RT-PCR validation of three genes related to plant hormone signal transduction. (JPG 173 kb)

Additional file 8: List of enriched GO categories in each comparison. (XLS $12995 \mathrm{~kb}$ )

Additional file 9: List of the DEGs expressed in 10 modules. (XLS $9181 \mathrm{~kb}$ ) Additional file 10: List of enriched GO categories in 10 modules. (XLS $2393 \mathrm{~kb}$ )

Additional file 11: List of the expressed TF genes. (XLS $4511 \mathrm{~kb}$ )

Additional file 12: Schematic diagram of the sampling position of cotton. (JPG $38 \mathrm{~kb}$ )

Additional file 13: List of primers used for qRT-PCR. (DOC $44 \mathrm{~kb}$ )

\section{Abbreviations}

ABA: abscisic acid; AUX1: auxin influx carrier; bHLH: basic helix-loop-helix; CAD: cinnamyl alcohol dehydrogenase; CCOAOMT1: S-adenosyl-L-methioninedependent methyltransferase superfamily protein; CK: cytokinin; CKX: cytokinin oxidase/dehydrogenase; COl1: an insensitive mutant of coronatine, jasmonate SCF-COI1 receptor complex; CTL2: chitinase-like protein 2; CTR1: serine/threonine protein kinase; DEG: differentially expressed gene; EIN2/3: ethylene-insensitive protein; ERF: ethylene response factor; ET: ethylene; ETR: ethylene receptor; EXP: expansion; F5H: ferulic acid 5hydroxylase; FDR: false discovery rate; GA: gibberellin; GH3: gretchenhagen-3; GO: Gene Ontology; IAA: indole-3-acetic acid; JA: jasmonic acid; JAR1: jasmonate synthetase; KEGG: Kyoto Encyclopedia of Genes and Genomes; LAC: laccase/diphenol oxidase family protein; LOF: loss of function; MAPKKK: mitogen-activated protein kinase kinase kinase; NCBI: National Center of Biotechnology Information; RNA-Seq: RNA Sequencing; RPKM: reads per kilobase per million reads; SAM: shoot apical meristem; SBH2: sphingoid base hydroxylase 2; TF: transcription factor; WAT1: the walls are thin1; XTH: xyloglucan endotransglucosylase /hydrolase; ZIM: ZIM domain protein; ZT: zeatin

\section{Acknowledgements}

We thank Gene Denovo Co. (Guangzhou, China) for assistance with sequencing and original data processing. This work was supported by the National Key R\&D Program of China (2018YFD0100406).

\section{Author' contributions}

$C P, Y Z$ and $X Z$ designed and oversaw the research. FJ and SL performed the research. FJ and $C P$ analyzed the results and wrote the manuscript. $X Z$ and YZ provided helpful suggestions during the data analysis. SZ, JC and QS provided suggestions during the article writing. HM provided help with cotton field management. CG and XZ provided helpful suggestions during qRT-PCR. All authors read and approved the final manuscript.

\section{Funding}

Funding for this work was provided by National Key R\&D Program of China (2018YFD0100406). Founding body had no role in the design of the study and collection, analysis, and interpretation of data and in writing the manuscript.

\section{Availability of data and materials}

The datasets supporting the conclusions of this article are included within the article and its additional files.

Ethics approval and consent to participate

Not applicable.

\section{Consent for publication}

Not applicable.

\section{Competing interests}

The authors declare that they have no competing interests.

Received: 28 February 2019 Accepted: 30 August 2019

Published online: 07 October 2019

\section{References}

1. Wang L, Mu C, Du M, Chen Y, Tian X, Zhang M, et al. The effect of mepiquat chloride on elongation of cotton (Gossypium hirsutum L.) internode is associated with low concentration of gibberellic acid. Plant Sci. 2014:225(8):15-23.

2. Fukino N, Ohara T, Sugiyama M, Kubo N, Hirai M, Sakata Y, et al. Mapping of a gene that confers short lateral branching $(s / b)$ in melon (Cucumis melo L.). Euphytica. 2012;187(1):133-43.

3. McSteen P, Leyser O. Shoot branching. Annu Rev Plant Biol. 2005:56:353-74.

4. Kaggwa-Asiimwe R, Andrade-Sanchez P, Wang G. Plant architecture influences growth and yield response of upland cotton to population density. Field Crop Res. 2013;145(4):52-9.

5. Marois JJ, Wright DL, Wiatrak PJ, Vargas MA. Effect of row width and nitrogen on cotton morphology and canopy microclimate. Crop Sci. 2004;44(3):870-7.

6. Kir G, Ye H, Nelissen H, Neelakandan AK, Kusnandar AS, Luo A, et al. RNA interference knockdown of BRASSINOSTEROID INSENSITIVE1 in maize reveals novel functions for brassinosteroid signaling in controlling plant architecture. Plant Physiol. 2015;169(1):826.

7. Leiboff S, Li X, Hu HC, Todt N, Yang J, Li X, et al. Genetic control of morphometric diversity in the maize shoot apical meristem. Nat Commun. 2015:6:8974.

8. Wang B, Smith SM, Li J. Genetic regulation of shoot architecture. Annu Rev Plant Biol. 2018;69:437-68.

9. Van der Knaap E, Kim JH, Kende H. A novel gibberellin-induced gene from rice and its potential regulatory role in stem growth. Plant Physiol. 2000;122 (3):695-704

10. Ayano M, Kani T, Kojima M, Sakakibara H, Kitaoka T, Kuroha T, et al. Gibberellin biosynthesis and signal transduction is essential for internode elongation in Deepwater rice. Plant Cell Environ. 2014;37(10):2313-24.

11. Zhang S, Hu W, Wang L, Lin C, Cong B, Sun C, et al. TFL1/CEN-like genes control intercalary meristem activity and phase transition in rice. Plant Sci. 2005;168(6):1393-408.

12. Si Z, Liu H, Zhu J, Chen J, Wang Q, Fang L, et al. Mutation of SELF-PRUNING homologs in cotton promotes short-branching plant architecture. J Exp Bot 2018;69(10):2543-53.

13. Chen M, Markham JE, Dietrich CR, Jaworski JG, Cahoon EB. Sphingolipid long-chain base hydroxylation is important for growth and regulation of sphingolipid content and composition in Arabidopsis. Plant Cell. 2008:20(7):1862-78.

14. Fujikura U, Elsaesser L, Breuninger $H$, Sánchez-Rodríguez C, Ivakov A, Laux T, et al. Atkinesin-13A modulates cell-wall synthesis and cell expansion in Arabidopsis thaliana via the THESEUS1 pathway. PLoS Genet. 2014;10(9):e1004627.

15. Li YJ, Zhu SH, Zhang XY, Liu YC, Xue F, Zhao LJ, et al. Expression and functional analyses of a Kinesin gene GhKIS13A1 from cotton (Gossypium hirsutum) fiber. BMC Biotechnol. 2017;17(1):50.

16. Bach L, Michaelson LV, Haslam R, Bellec Y, Gissot L, Marion J, et al. The very-long-chain hydroxy fatty acyl-CoA dehydratase PASTICCINO2 is essential and limiting for plant development. Proc Natl Acad Sci U S A. 2008;105(38):14727-31.

17. Mansell RL, Babbel GR, Zenk MH. Multiple forms and specificity of coniferyl alcohol from cambial e-hydrogenase regions of higher plants. Phytochemistry. 1976;15(12):1849-53. 
18. Hossain MA, Noh HN, Kim Kl, Koh EJ, Wi SG, Bae HJ, et al. Mutation of the chitinase-like protein-encoding AtCTL2 gene enhances lignin accumulation in dark-grown Arabidopsis seedlings. J Plant Physiol. 2010;167(8):650-8.

19. Berthet $S$, Demont-Caulet N, Pollet B, Bidzinski $P$, Cézard L, Le Bris $P$, et al. Disruption of LACCASE4 and 17 results in tissue-specific alterations to lignification of Arabidopsis thaliana stems. Plant Cell. 2011;23(3):1124-37.

20. Zhao Q, Nakashima J, Chen F, Yin Y, Fu C, Yun J, et al. LACCASE is necessary and nonredundant with PEROXIDASE for lignin polymerization during vascular development in Arabidopsis. Plant Cell. 2013;25(10):3976-87.

21. Barbez E, Dünser K, Gaidora A, Lendl T, Busch W. Auxin steers root cell expansion via apoplastic pH regulation in Arabidopsis thaliana. Proc Natl Acad Sci U S A. 2017;114(24):E4884-93.

22. Günesdogan $U$, Jäckle $H$, Herzig A. Histone supply regulates $S$ phase timing and cell cycle progression. eLife,3,(2014-08-11), 2014, 3(3):e02443.

23. Nardi CF, Villarreal NM, Rossi FR, Martínez S, Martínez GA, Civello PM Overexpression of the carbohydrate binding module of strawberry expansin2 in Arabidopsis thaliana modifies plant growth and cell wall metabolism. Plant Mol Biol. 2015;88(1-2):101-17.

24. Ranocha P, Denancé N, Vanholme R, Freydier A, Martinez Y, Hoffmann L, et al. Walls are thin 1 (WAT1), an Arabidopsis homolog of Medicago truncatula NODULIN21, is a tonoplast-localized protein required for secondary wall formation in fibers. Plant J. 2010;63(3):469-83.

25. Shin YK, Yum H, Kim ES, Cho H, Gothandam KM, Hyun J, et al. BCXTH1, a Brassica campestris homologue of Arabidopsis XTH9, is associated with cell expansion. Planta. 2006;224(1):32-41.

26. Little CHA, Pharis RP. 13-hormonal control of radial and longitudinal growth in the tree stem. Plant Stems. 1995;4:281-319.

27. Wolters $H$, Jürgens $G$. Survival of the flexible: hormonal growth control and adaptation in plant development. Nat Rev Genet. 2009;10(5):305-17.

28. Hagen G. Auxin signal transduction. Essays in Biochemistry volume. 2015;58:1-12.

29. Woodward AW, Bartel B. Auxin: regulation, action, and interaction. Ann Bot. 2005:95(5):707-35.

30. Marchant A, Kargul J, May ST, Muller P, Delbarre A, Perrot-Rechenmann C, et al. AUX1 regulates root gravitropism in Arabidopsis by facilitating auxin uptake within root apical tissues. EMBO J. 1999;18(8):2066-73.

31. Swarup R, Friml J, Marchant A, Ljung K, Sandberg G, Palme K, et al. Localization of the auxin permease AUX1 suggests two functionally distinct hormone transport pathways operate in the Arabidopsis root apex. Genes Dev. 2001;15(20):2648-53.

32. Ding $X$, Cao $Y$, Huang $L$, Zhao J, Xu C, Li X, et al. Activation of the indole-3acetic acid amido synthetase GH.8 suppresses expansin expression and promotes salicylate and jasmonate-independent basal immunity in rice. Plant Cell. 2008;20(1):228-40.

33. Staswick PE, Serban B, Rowe M, Tiryaki I, Maldonado MT, Maldonado MC et al. Characterization of an Arabidopsis enzyme family that conjugates amino acids to indole-3-acetic acid. Plant Cell. 2005;17(2):616-27.

34. Park JE, Park JY, Kim YS, Staswick PE, Jeon J, Yun J, et al. GH3-mediated auxin homeostasis links growth regulation with stress adaptation response in Arabidopsis. J Biol Chem. 2007;282(13):10036-46.

35. Mattoo AK, Suttle JC, Eds. The plant hormone ethylene. Boca Raton, FA: CRC Press, Inc. 1991.

36. Cox WJ, Andrade HF. Growth yield and yield components of maize as influenced by ethephon. Crop Sci. 1988;28(3):536-42.

37. Kasele IN, Nyirenda F, Shanahan JF, Nielsen DC, D'Andria R. Ethephon alters corn growth, water use, and grain yield under drought stress. Agron J. 1994:86(2):283-8.

38. D'Andria R, Quaglietta CF, Lavini A, Mori M. Grain yield and water consumption of ethephon-treated corn under different irrigation regimes. Agron J. 1997;89(1):104-12.

39. Earley EB, Slife FW. Effect of ethylene on growth and yield of corn. Agron J. 1969;61(5):821-3.

40. Norberg OS, Mason SC, Lowry SR. Ethephon influence on harvestable yield, grain quality, and lodging of corn. Agron J. 1988;80(5):768-72.

41. Woodward EJ, Marshall C. Effects of plant growth regulators and nutrient supply on tiller bud outgrowth in barley (Hordeum distichum L.). Ann Bot. 1988;61(3):347-54.

42. Jackson MB. Ethylene in root growth and development. Plant Hormone Ethylene, 1991.

43. Wei X, Zhang W, Zhang Q, Sun P, Li Z, Zhang M, et al. Analysis of differential expression of genes induced by ethephon in elongating internodes of maize plants. Front Agr Sci Eng. 2016;3(3):263-82.
44. Lin M, Pang C, Fan S, Song M, Wei H, Yu S. Global analysis of the Gossypium hirsutum $L$ transcriptome during leaf senescence by RNA-Seq. BMC Plant Biol. 2015;15:43.

45. Alonso JM, Hirayama T, Roman G, Nourizadeh S, Ecker JR. EIN2, a bifunctional transducer of ethylene and stress responses in Arabidopsis. Science. 1999;284(5423):2148-52

46. Solano R, Stepanova A, Chao Q, Ecker JR. Nuclear events in ethylene signaling: a transcriptional cascade mediated by ETHYLENE-INSENSITIVE3 and ETHYLENE-RESPONSE-FACTOR1. Genes Dev. 1998;12(23):3703-14.

47. Fujimoto SY, Ohta M, Usui A, Shinshi H, Ohme-Takagi M. Arabidopsis ethylene-responsive element binding factors act as transcriptional activators or repressors of GCC box-mediated gene expression. Plant Cell. 2000;12(3):393-404.

48. Ohme-Takagi M, Shinshi $H$. Ethylene-inducible DNA binding proteins that interact with an ethylene-responsive element. Plant Cell. 1995;7 (2): $173-82$

49. Song S, Qi T, Wasternack C, Xie D. Jasmonate signaling and crosstalk with gibberellin and ethylene. Curr Opin Plant Biol. 2014:112-9.

50. Staswick PE, Su W, Howell SH. Methyl jasmonate inhibition of root growth and induction of a leaf protein are decreased in an Arabidopsis thaliana mutant. Proc Natl Acad Sci U S A. 1992:89(15):6837-40.

51. Pauwels L, Morreel K, De Witte E, Lammertyn F, Van Montagu M, Boerjan W, et al. Mapping methyl jasmonate-mediated transcriptional reprogramming of metabolism and cell cycle progression in cultured Arabidopsis cells. Proc Natl Acad Sci U S A. 2008;105(4):1380-5.

52. Chen Q, Sun J, Zhai Q, Zhou W, Qi L, Xu L, et al. The basic helix-loop-helix transcription factor MYC2 directly represses P LETHORA expressionduring jasmonate-mediated modulation of the root stem cell niche in Arabidopsis. Plant Cell. 2011;23(9):3335-52.

53. Keshishian EA, Rashotte AM. Plant cytokinin signalling. Essays in Biochemistry volume. 2015;58:13-27.

54. Köllmer I, Novák O, Strnad M, Schmülling T, Werner T. Overexpression of the cytosolic cytokinin oxidase/dehydrogenase (CKX7) from Arabidopsis causes specific changes in root growth and xylem differentiation. Plant J. 2014;78(3):359-71.

55. Schaller GE, Street IH, Kieber JJ. Cytokinin and the cell cycle. Curr Opin Plant Biol. 2014;21(21C):7-15.

56. Schmülling T, Werner T, Riefler M, Krupková E, Bartrina y Manns I. Structure and function of cytokinin oxidase/dehydrogenase genes of maize, rice, Arabidopsis and other species. J Plant Res. 2003;116(3):241-52.

57. Zhang C, Xu Y, Lu Y, Yu H, Gu M, Liu Q. The WRKY transcription factor OsWRKY78 regulates stem elongation and seed development in rice. Planta. 2011;234(3):541-54.

58. Yu Y, Liu Z, Wang L, Kim SG, Seo PJ, Qiao M, et al. WRKY71 accelerates flowering via the direct activation of FLOWERING LOCUS T and LEAFY in Arabidopsis thaliana. Plant J. 2016;85(1):96-106.

59. Yu F, Huaxia Y, Lu W, Wu C, Cao X, Guo X. GhWRKY15, a member of the WRKY transcription factor family identified from cotton (Gossypium hirsutum L.), is involved in disease resistance and plant development. BMC Plant Biol. 2012;12:144

60. Riechmann JL, Meyerowitz EM. The AP2/EREBP family of plant transcription factors. Biol Chem. 1998;379(6):633-46.

61. Hattori $Y$, Nagai $K$, Furukawa S, Song X, Kawano R, Sakakibara H, et al. The ethylene response factors SNORKEL1 and SNORKEL2 allow rice to adapt to deep water. Nature. 2009;460(7258):1026-30.

62. Xu K, Xu X, Fukao T, Canlas P, Maghirang-Rodriguez R, Heuer S, et al. Sub1A is an ethylene-response-factor-like gene that confers submergence tolerance to rice. Nature. 2006:442:705-8.

63. Qi W, Sun F, Wang Q, Chen M, Huang Y, Feng Y, et al. Rice ethyleneresponse $A P 2 / E R F$ factor OSEATB restricts internode elongation by down-regulating a gibberellin biosynthetic gene. Plant Physiol. 2011; 157(1):216-28.

64. Toledo-Ortiz G, Huq E, Quail PH. The Arabidopsis basic/helix-loop-helix transcription factor family. Plant Cell. 2003;15(8):1749-70.

65. Zhang L, Bai M, Wu J, Zhu J, Wang H, Zhang Z, et al. Antagonistic HLH/bHLH transcription factors mediate brassinosteroid regulation of cell elongation and plant development in rice and Arabidopsis. Plant Cell. 2009;21(12):3767-80.

66. Komatsu K, Maekawa M, Ujiie S, Satake Y, Furutani I, Okamoto H, et al. LAX and SPA: major regulators of shoot branching in rice. Proc Natl Acad Sci U S A. 2003;100(20):11765-70. 
67. Zhang T, Hu Y, Jiang W, Fang L, Guan X, Chen J, et al. Sequencing of allotetraploid cotton (Gossypium hirsutum L. acc. TM-1) provides a resource for fiber improvement. Nat Biotechnol. 2015;33(5):531-7.

68. Livak KJ, Schmittgen TD. Analysis of relative gene expression data using realtime quantitative PCR and the $2^{-\Delta \Delta C T}$ method. Methods. 2001;25(4):402-8.

69. Pan X, Welti R, Wang X. Quantitative analysis of major plant hormones in crude plant extracts by high-performance liquid chromatography-mass spectrometry. Nat Protoc. 2010;5(6):986-92.

\section{Publisher's Note}

Springer Nature remains neutral with regard to jurisdictional claims in published maps and institutional affiliations.

Ready to submit your research? Choose BMC and benefit from:

- fast, convenient online submission

- thorough peer review by experienced researchers in your field

- rapid publication on acceptance

- support for research data, including large and complex data types

- gold Open Access which fosters wider collaboration and increased citations

- maximum visibility for your research: over $100 \mathrm{M}$ website views per year

At $\mathrm{BMC}$, research is always in progress.

Learn more biomedcentral.com/submissions 